\title{
man \\ Identification of Aluminium Powder Properties for Modelling Free Air Explosions
}

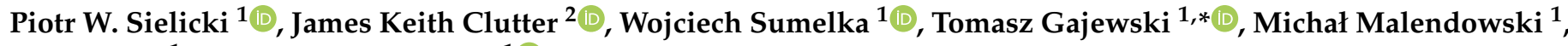 \\ Piotr Peksa ${ }^{1}$ and Robert Studziński ${ }^{1}$ (i) \\ 1 Faculty of Civil and Transport Engineering, Poznan University of Technology, Maria Sklodowska-Curie \\ Street 5, 60-965 Poznan, Poland; piotr.sielicki@put.edu.pl (P.W.S.); wojciech.sumelka@put.poznan.pl (W.S.); \\ michal.malendowski@put.poznan.pl (M.M.); piotr.peksa@put.poznan.pl (P.P.); \\ robert.studzinski@put.poznan.pl (R.S.) \\ 2 SciRisq, Inc., 448 W. 19th St., \#210, Houston, TX 77008, USA; keith.clutter@scirisq.com \\ * Correspondence: tomasz.gajewski@put.poznan.pl
}

Citation: Sielicki, P.W.; Clutter, J.K. Sumelka, W.; Gajewski, T.; Malendowski, M.; Peksa, P.; Studziński, R. Identification of Aluminium Powder Properties for Modelling Free Air Explosions. Materials 2022, 15, 1294. https:// doi.org/10.3390/ma15041294

Academic Editor: Bolv Xiao

Received: 30 December 2021

Accepted: 6 February 2022

Published: 10 February 2022

Publisher's Note: MDPI stays neutral with regard to jurisdictional claims in published maps and institutional affiliations.

Copyright: (C) 2022 by the authors. Licensee MDPI, Basel, Switzerland. This article is an open access article distributed under the terms and conditions of the Creative Commons Attribution (CC BY) license (https:// creativecommons.org/licenses/by/ $4.0 /)$.

\begin{abstract}
Aluminium is a component in many energetic formulations. Therefore, its combustion is one of the main thermochemical processes that govern the output from the energetics. Modelling aluminium combustion is a challenging task because the process is highly complex and difficult to measure. Here, tests of aluminium powder were conducted in an effort to isolate the burning of the aluminium and to determine an adequate representation of this process. Charges of $100 \mathrm{~g}$ and $500 \mathrm{~g}$ were tested, and the size of the $\mathrm{Al} /$ air cloud and the ratio of components in the $\mathrm{Al} /$ air mixture were determined, which has not been published previously. This information was used to assess the validity of the assumption that the detonation of the mixture was representative of the event. Parameters for the Jones-Wilkins-Lee equation of state for the explosive mixture and detonation products were defined. Simulations of the tests were performed, and the results were consistent with the field test data, indicating that detonation occurred when there was a mixture of $70-75 \% \mathrm{Al}$ and $25-30 \%$ air by mass.
\end{abstract}

Keywords: aluminium powder; detonation; explosive; combustion; oxidation; equation of state

\section{Introduction}

The composition of an explosive is a key factor in its efficiency. Most standard military explosives and those used in research operations are condensed explosives, such as trinitrotoluene (TNT) and Plastic Explosive No. 4 (PE4). These substances are ideal for contact explosions due to their brisance and high-intensity shock wave propagation. Furthermore, they can be altered in different ways to change their explosive performances. One common alteration is the addition of various components, such as aluminium (Al) powder [1-3].

The addition of aluminium changes the energy release process and the overall output of an explosive at the microscopic level. Additionally, the ignition and combustion properties of an explosive can be modified, as shown by Liu et al. [4], by coating it with nanosized aluminium particles. Oxidation plays a crucial role in the combustion of aluminium. Gang et al. investigated the combustion and oxidation of Al nanoparticles at the atomistic level [5]. Depending on the amount of $\mathrm{O}_{2}$ and the temperature, oxidation can be grouped into three categories: mild, chain-like growth oxidation; moderate oxidation; and microexplosion-accelerated oxidation. The microexplosion-accelerated oxidation mechanism was investigated deeply by Gang et al. The burning of separated Al droplets in air was studied by Karasev et al. [6], as well as the mechanisms involved in alumina aggregate formation.

However, the microscopic level is not the only level of interest in terms of energy release processes; the combustion of aluminium nanoparticles has also been investigated at 
the macroscopic level. For instance, Lewis et al. [7] studied hexahydro-1,3,5-trinitro-1,3,5triazine (RDX) explosives with three types of aluminium nanoparticles. They showed that the addition of the nanoparticles can change the fireball temperature from $340 \mathrm{~K}$ to $4500 \mathrm{~K}$. Gordon et al. [8] also studied the fireball of aluminised RDX, in addition to its shock wave energy. The authors reported that the shock energy is greater if aluminium is added to the high explosive rather than to the liner. Other studies of aluminised high explosives were conducted by Peuker et al. [9] and Carney et al. [10], in which optical methods were used. In the current study, the afterburn phase was analysed.

The contribution of $\mathrm{Al}$ combustion to the afterburn phase of aluminised explosives has been represented in various studies [11] using the Jones-Wilkins-Lee (JWL)-Miller model [12]. This model alters the energy term in the JWL equation such that it has the form

$$
P=A\left(1-\frac{\omega}{R_{1} V}\right) e^{-R_{1} V}+B\left(1-\frac{\omega}{R_{2} V}\right) e^{-R_{2} V}+\frac{\omega(E+\lambda Q)}{V},
$$

where $Q$ is the additional heat released by the aluminium particle combustion, and $\lambda$ is the progression variable indicating the degree to which the particle has reacted. The degree of reaction equation is given by

$$
\frac{d \lambda}{d t}=a(1-\lambda)^{m} P^{n}
$$

where $a$ depends on the particle size, and $m$ and $n$ are reaction rate constants. This model represents the gradual addition of energy seen in the afterburn phase rather than the sudden release of energy observed in the aluminium powder explosives. Here, the rate of gasification, which is associated with the combustion rate equation, is relevant.

Other models have been introduced that also replicate the afterburn energy release due to $\mathrm{Al}$ combustion, but they assume that the reaction is proportional to the gasification of the particles [13]. This process is explicitly represented by the change in the diameter of the particles, which can be expressed as

$$
\frac{d}{d t}\left[\frac{4}{3} \pi\left(\frac{D}{2}\right)^{3} \rho\right]=4 \pi\left(\frac{D}{2}\right)^{2} \dot{m_{v}}
$$

which simplifies to

$$
D=D_{0}-\frac{2 \dot{m_{v}}}{\rho} t
$$

where $D$ is the particle diameter, $D_{0}$ is the initial particle diameter, and $m_{v}$ is the gasification rate of the condensed material, which can be expressed as

$$
\dot{m_{v}}=\frac{\sqrt{3}}{2 \pi r^{3}} \sqrt{k T m} e^{-E_{v} / R T},
$$

where $r$ is the radius of the molecule, $m$ is the mass of each molecule, $k$ is the Boltzmann constant $\left(1.38 \times 10^{-23} \mathrm{~J} / \mathrm{K}\right), T$ is the temperature, $E_{v}$ is the gasification enthalpy, and $R$ is the gas constant $(8.314 \mathrm{~J} / \mathrm{mol} \cdot \mathrm{K})$. follows

The afterburn combustion of $\mathrm{Al}$ can be used to redefine the degree of reaction, as

$$
\lambda=1-\left(1-\frac{2 \dot{m}_{v} t}{\rho_{A l} D_{0}}\right)^{3},
$$

where $\dot{m}_{v}$ is the gasification rate, $t$ is time, $\rho_{A l}$ is density of aluminum, and $D_{0}$ is initial diameter.

Another group of models address the gasification of the Al particles using an empirical quasi-steady law [14]. The particle radius $\left(r_{p}\right)$ rate is

$$
\frac{d r_{p}}{d t}=-\frac{r_{p}}{t_{b}}(1+0.276 \sqrt{R e})
$$


where $R e$ is the Reynolds number, which is based on the relative velocity between the gas and the particle, and $t_{b}$ is the burning time based on

$$
t_{b}=K\left(D_{0}\right)^{2},
$$

where $K$ is an empirical constant. According to the literature, $K$ is typically set equal to $4 \times$ $10^{6} \mathrm{~s} / \mathrm{m}^{2}$. The mass transfer from the solid to gaseous state is

$$
\frac{d m_{p}}{d t}=-\frac{d}{d t}\left(\frac{4}{3} \pi \rho_{p} r_{p}^{3}\right),
$$

where the subscript $p$ denotes the particle properties.

In the current study, the temperature of ignition depends on the state of the Al particles. If an oxide coating is present and is not cracked through some sort of physical process, then the melting point of $\mathrm{Al}_{2} \mathrm{O}_{3}$ would determine ignition. This melting point is approximately $2050 \mathrm{~K}$. If the oxide layer is cracked, then the ignition temperature would be determined by the melting point of $\mathrm{Al}$, which is approximately $950 \mathrm{~K}$.

The temperature of the particles will depend on the heat feedback from the gas phase to the condensed phase. An investigation of aluminised explosives [15] has shown that the feedback can be represented using Fourier's law

$$
q_{c}=\alpha_{g}\left(\frac{1}{r}\right)\left(\frac{d T}{d t}\right)_{s},
$$

where $\alpha_{g}$ is the thermal conductivity, $r$ is the burning rate, and $s$ denotes the gradient at the surface.

Hence, an understanding of the energy released during aluminium combustion is key to optimising the design of energetic systems and would allow the quantification of aluminium's effect on structures. In this paper, aluminium powder was analysed at the macroscopic level; this approach enables the straightforward development of online (fast) tools that can predict the behaviour of aluminium powder explosives. The current objective was to develop an adequate representation of $\mathrm{Al}$ combustion to provide loading predictions for use in the analysis of the interaction between munitions and structures. From this point of view, the robust modelling of such explosives is no trivial task.

Equations of state (EOS) are a key concept in modelling this class of energetics. Various EOS approaches are found in the literature. They have been proposed for aluminised explosive products [16], along with more popular approaches, such as the JWL formula [17-19]. The JWL approach is well known and has the broadest application; thus, it was adopted in the current study. Here, the expansion process of the detonation products from the composite energetics was determined to be crucial. This expansion process affects the prediction of the pressure loading at a particular distance, which is an essential characteristic in determining the effect of the explosive.

This paper analysed the combustion of $\mathrm{Al}$, as this critical process affects the energy outputs of aluminised explosives. The oxidiser that was used in the tests varied according to the specifics of the energetics. In most explosives, the oxidiser is obtained from the products of the organic reaction that forms $\mathrm{CO}, \mathrm{CO}_{2}$, and $\mathrm{H}_{2} \mathrm{O}$. It has been shown that $\mathrm{Al}$ combustion is determined by the concentrations of $\mathrm{CO}_{2}$ and $\mathrm{H}_{2} \mathrm{O}$ [20]. Therefore, $\mathrm{Al}$ combustion often occurs before any ambient oxidiser is introduced to the Al. Here, pure $\mathrm{Al}$ was used to ensure that the oxidation process was related to the mixing of $\mathrm{Al}$ powder with ambient air. This provided insights into the combustion of $\mathrm{Al}$, even when the oxidiser originated from typical detonation products.

In this study, a series of range detonation tests with pure aluminium powder mixtures were performed, which has not been published previously. The mass of the charges varied from 0.1 to $0.5 \mathrm{~kg}$. The primary goal of the tests was to measure the pressure-time histories, and these results were replicated using modelling tools. Seven tests were performed, and 
full data recordings were obtained at standoff distances of approximately 1 and $2 \mathrm{~m}$. The tests were replicated using a modelling tool that incorporated the effects of Al combustion. The EOS and reaction parameters were first defined using thermodynamic codes and analytical tools. Subsequently, as described in the final part of this paper, these values were altered to match the test results.

The paper is structured as follows. In Section 2, the test details, computational assumptions, and an explosive governing equation are presented. Section 3 identifies the explosive parameters for the $100 \mathrm{~g}$ charge and presents their validation for the $500 \mathrm{~g}$ charge. Section 4 presents the conclusions of the study.

\section{Materials and Methods}

\subsection{Field Test Measurements}

In this section, data from the field tests for the $100 \mathrm{~g}$ and $500 \mathrm{~g}$ aluminium powder charge detonation are described. The experiments were conducted so as to represent a free air blast. Data from the $100 \mathrm{~g}$ detonation were used to determine the aluminium modelling parameters. The tests were performed using $6 \mu \mathrm{m}$ of Al powder with an estimated density of 2.2 to $2.7 \mathrm{~g} / \mathrm{cc}$. The aluminium powder is shown in Figure 1a. Photographs from the test site are presented in Figure 1b,c, including a snapshot of the explosion (Figure 1b) and an overview of the explosion area (framed by wooden poles), along with the high-speed camera (Figure 1c). Figure 1d presents details of the explosive devices' mounting scheme. The aluminium powder was hung in a foil bag attached to a string and was located $100 \mathrm{~cm}$ from the ground (L) directly between two wooden poles that were $200 \mathrm{~cm}$ high $(\mathrm{H})$. The distance between the poles was $500 \mathrm{~cm}(\mathrm{~W})$. Blast pressure pencil probes were placed at heights of $100 \mathrm{~cm} \mathrm{(b)} \mathrm{and} 200 \mathrm{~cm}$ (a) from the charge.

Seven detonations were conducted during the field tests. In the first two detonations, the aluminium powder charge mass was $100 \mathrm{~g}$; in the next two, the charge mass was $200 \mathrm{~g}$, and in the last three, the charge mass was $500 \mathrm{~g}$. The data from the second $200 \mathrm{~g}$ detonation were rejected. In this case, during aluminium combustion, the foil bag was damaged, and the powder poured out of the bag. Thus, the data could not be considered for further analysis. Because the $200 \mathrm{~g}$ case was not represented by two detonations, this charge mass was not taken into account in the subsequent analyses.

(a)

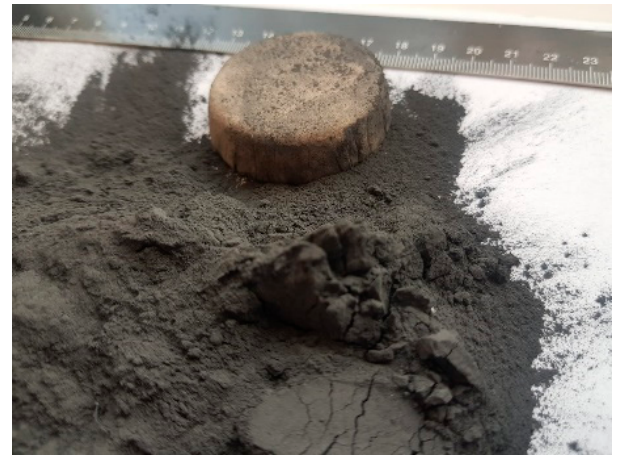

(b)

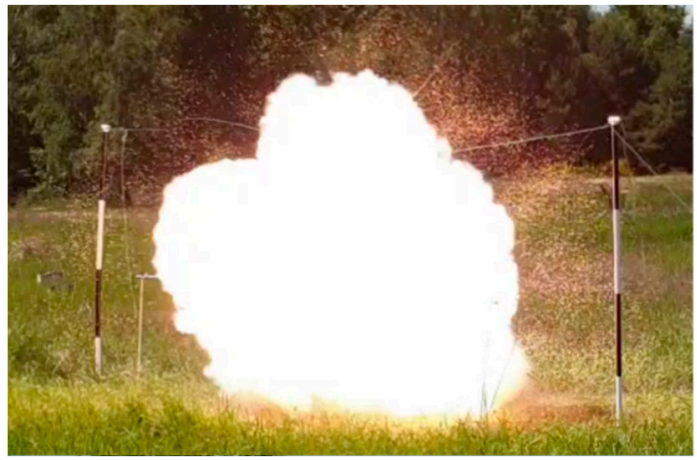

Figure 1. Cont. 
(c)

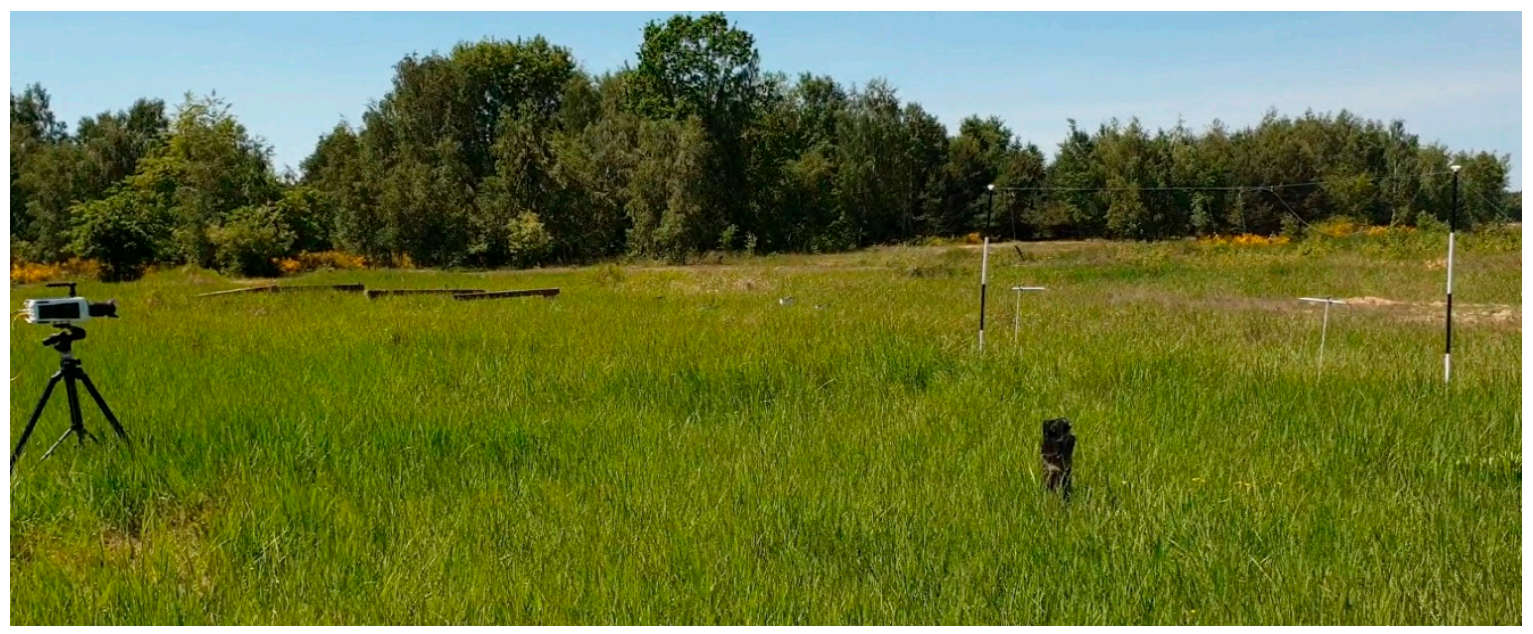

(d)

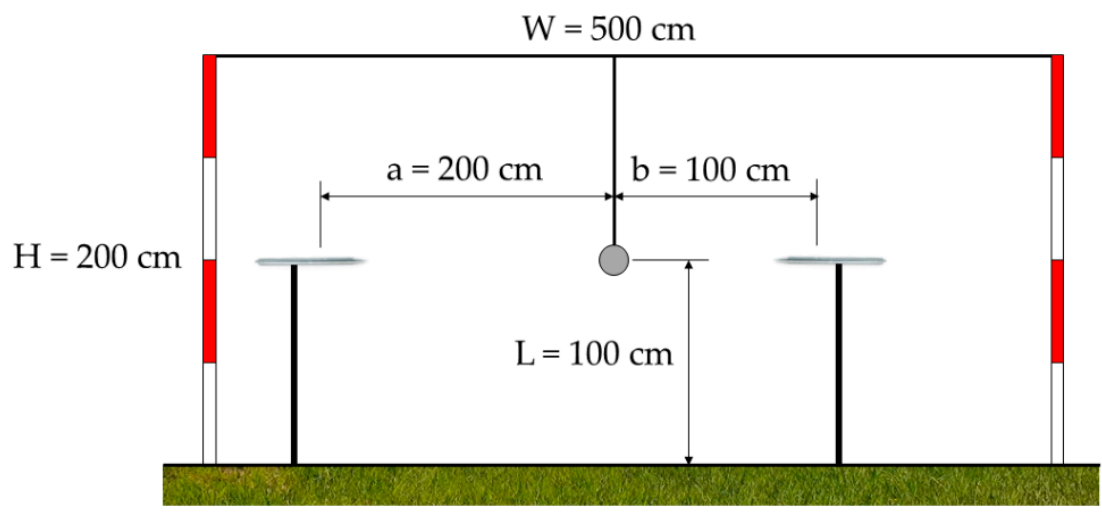

Figure 1. Test set up: (a) example of tested mixture of aluminium powder; (b) snapshot of the explosion; (c) overview of the explosion area; and (d) explosive devices' mounting scheme.

The pressure-time histories from all tests were measured at 1 and $2 \mathrm{~m}$ from the explosive simultaneously. Two ICP ${ }^{\circledR}$ blast pressure pencil probes were used simultaneously to acquire the data-these are the same probes that were used in [21]. The maximum pressure limit for these sensors is $345 \mathrm{kPa}$. The results are shown in Figures 2 and 3. All measurements are presented, including those that were rejected (i.e., pressure histories no. $3(200 \mathrm{~g})$ and no. 4 (labelled as Err, i.e., error)).

The detonations were filmed with a high-speed camera to obtain deeper insights into the reaction process to ensure adequate modelling assumptions. In these types of experiments, a high-speed camera is typically used to assess the deformation due to the blast wave [22] and determine the speed of projectiles and fragments, e.g., [23,24]. In our tests, the high-speed camera was used to estimate the volume of the mixed powder. Figure 4 shows sample images captured immediately after detonation. The time after ignition is shown next to the sequence of images. Powder burning at the time of ignition and thereafter can be observed. 


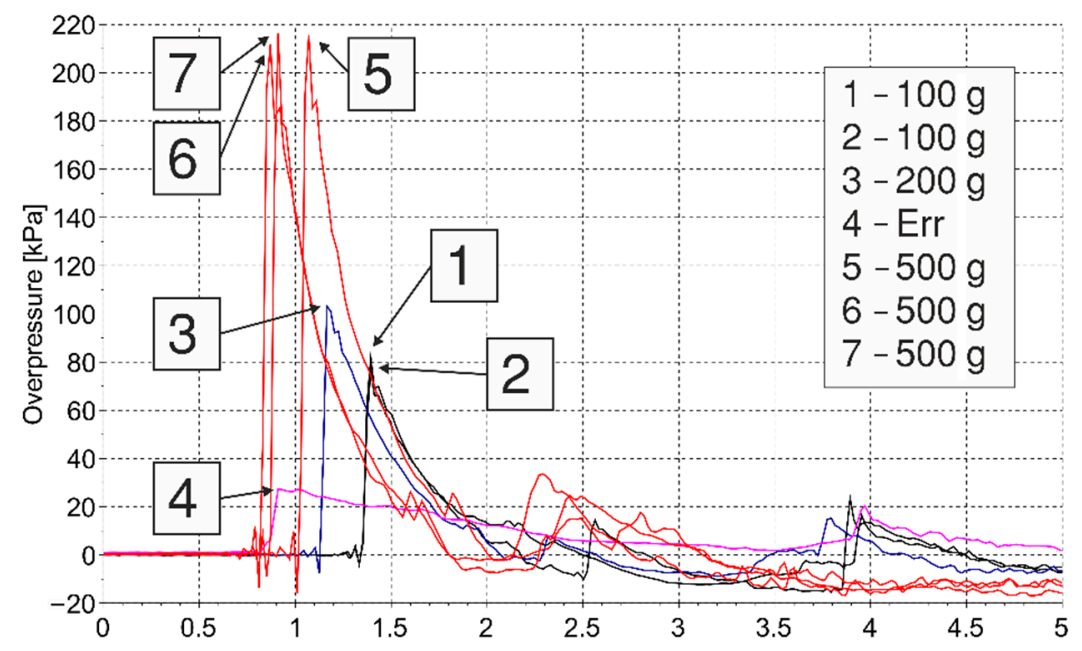

Figure 2. Overpressure measurements at $1 \mathrm{~m}$.

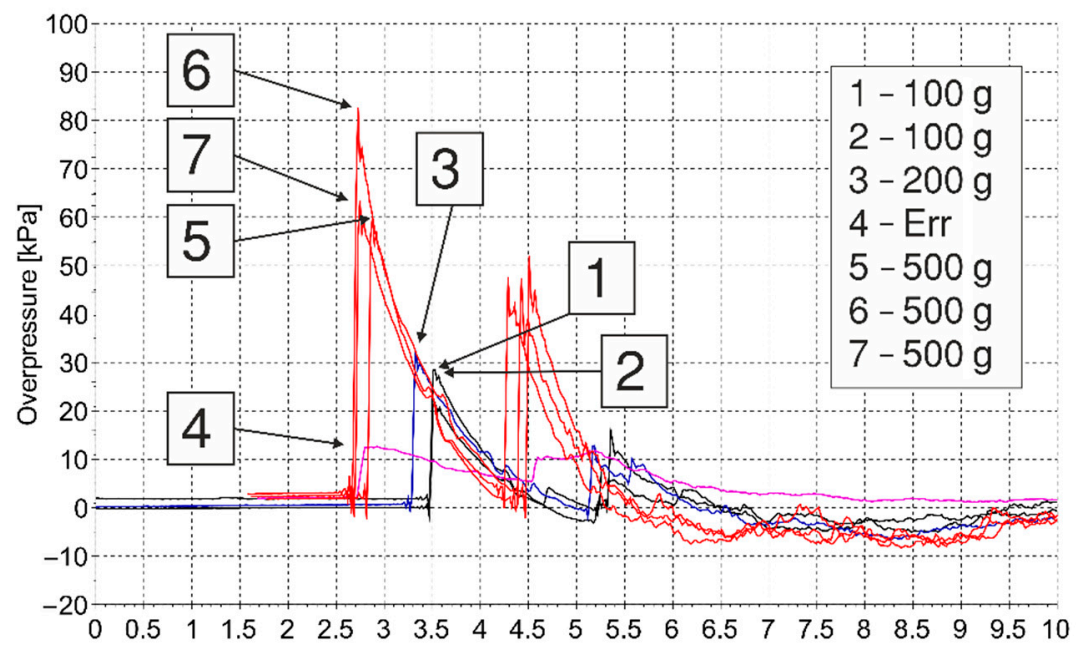

Figure 3. Overpressure measurements at $2 \mathrm{~m}$.
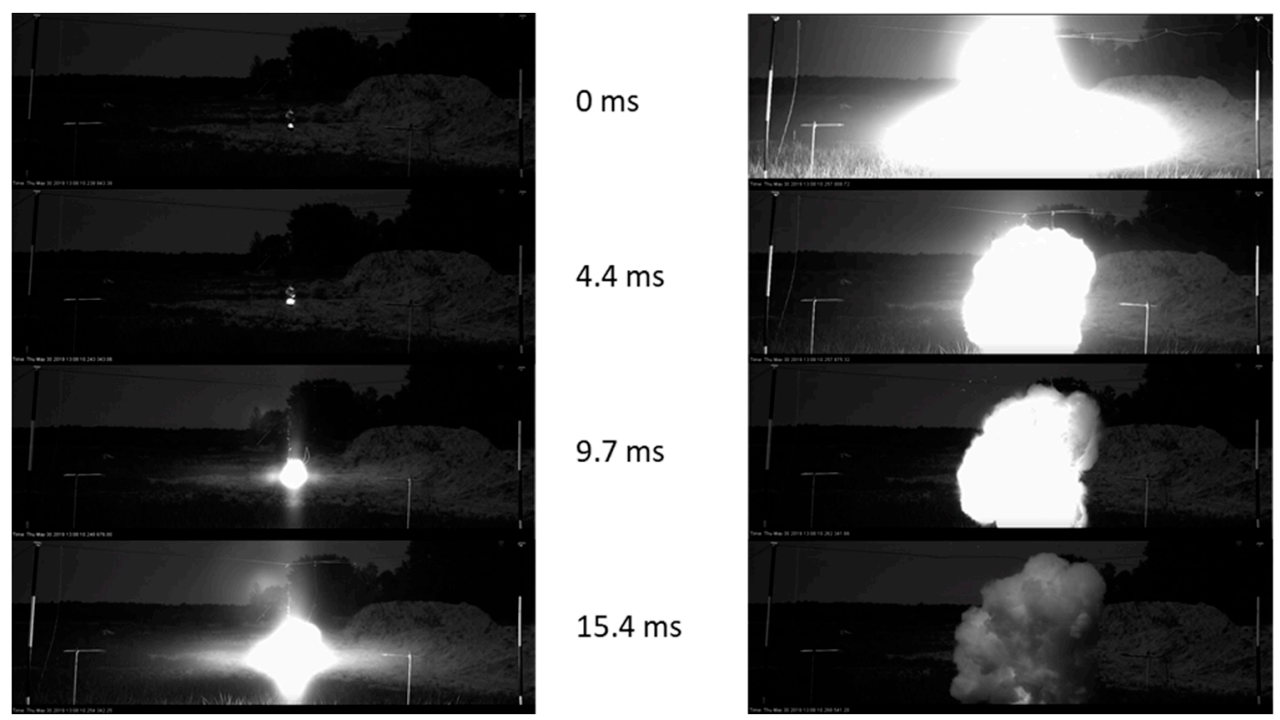

$18.1 \mathrm{~ms}$

$18.9 \mathrm{~ms}$

$23.4 \mathrm{~ms}$

$29.6 \mathrm{~ms}$

Figure 4. Sequence of images from the $100 \mathrm{~g}$ test. The time presented refers to the time after ignition. 
If a spherical charge is assumed and the $\mathrm{Al}$ density is $2.7 \mathrm{~g} / \mathrm{cc}$, the volume of the initial charge would be $37.04 \mathrm{cc}$, and the charge would have a diameter of $2.07 \mathrm{~cm}$. Notably, there was an apparent spike in output at the $18.1 \mathrm{~ms}$ mark. The $\mathrm{Al} /$ air cloud at the $18.1 \mathrm{~ms}$ mark had a diameter of approximately $41.4 \mathrm{~cm}$ and a volume of $37.15 \mathrm{cc}$. This resulted in an $\mathrm{Al}$ density of $2.69 \times 10^{-3} \mathrm{~g} / \mathrm{cc}$. Taking the air to be at atmospheric pressure, the volume of powder and air would contain a mixture of $56 \% \mathrm{Al}$ and $44 \%$ air considering masses. This information was used to derive an adequate representation of the explosion process.

The overall pattern for the $500 \mathrm{~g}$ tests was similar to that of the $100 \mathrm{~g}$ tests. For the $500 \mathrm{~g}$ charge, the "explosion" (rapid release of energy) appeared to occur between 2.3 and $5.8 \mathrm{~ms}$ after ignition. The diameter of the $\mathrm{Al} /$ air cloud at that time varied from 40 to $54 \mathrm{~cm}$. Figure 5 shows an image taken after the "explosion" of the $500 \mathrm{~g}$ Al charge. More burning particles of Al were expelled outward after the "explosion" (white arrows) of the $500 \mathrm{~g}$ charge compared to that of the $100 \mathrm{~g}$ charge, suggesting that the $500 \mathrm{~g}$ charge was less effective than the $100 \mathrm{~g}$ charge. The analysis of the $500 \mathrm{~g}$ test data allowed an adequate representation of the $\mathrm{Al}$ combustion to be determined.

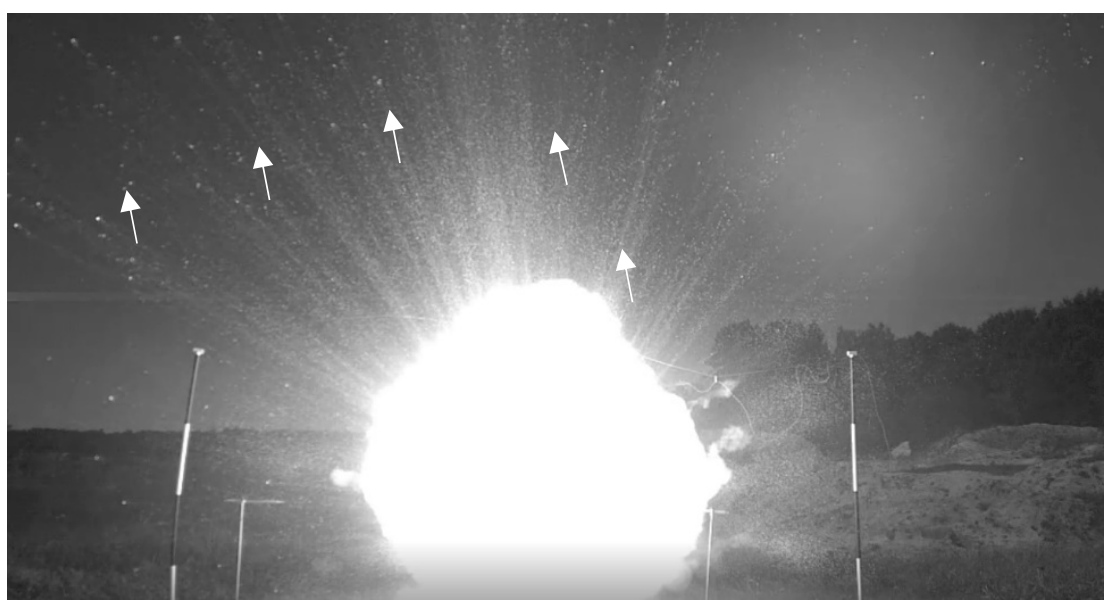

Figure 5. Image of the $500 \mathrm{~g}$ test (Test 7), in which burning $\mathrm{Al}$ particles (white arrows) were expelled.

\subsection{Numerical Modelling Assumptions}

The computational model that was developed to simulate the energetics used a Cartesian Adaptive Mesh (CAM) framework; this model simulates scenarios involving a blast, explosion, and release of materials (thus, CAMBER). CAMBER is an object-oriented framework that utilises a variety of material models and reaction laws. The mesh adaptation was used to resolve structures under severe deformation, and the code maps out the locations of gradients in properties [25]. In CAMBER, a finite-volume formulation is used. Various flux calculation schemes have been assessed and proven to be useful in multi-material flows [26]. The advection upstream splitting method (AUSM+) scheme was selected for its simplicity and robustness [27]; high spatial order is achieved via a monotonic upstreamcentred scheme for conservation law (MUSCL) extrapolation with limiters. Given the small time steps required to resolve the evolving flow field, explicit time integration was used. The code can be applied in 2D, 2D-axisymmetric, or 3D modes.

\subsection{Governing Equation for Explosions}

The objective of this study was to formulate an approach to simulate explosions involving aluminium. The energetics used in the present research were for pure aluminium, so the reaction causing the energy release was as follows

$$
4 \mathrm{Al}+3 \mathrm{O} \rightarrow 2 \mathrm{Al}_{2} \mathrm{O}_{3}
$$

Hence, if $\mathrm{Al}$ is part of the explosive composition, the oxidation could arise from the $\mathrm{CO}_{2}$ and $\mathrm{H}_{2} \mathrm{O}$ in the detonation product. In this case, the oxidiser was the $\mathrm{O}_{2}$ in the air. 
There was clearly burning Al prior to the "explosion" at $18.1 \mathrm{~ms}$ (see Figure 4), but at this time point, there was a sudden release of energy. It can be assumed that until this time point, the percentage of Al burned was negligible. Furthermore, the assumption was made that the explosive cloud was 56\% $\mathrm{Al}$ and $44 \%$ air by mass (as described in Section 2.1).

A thermochemical analysis was performed as a first estimate; it was assumed that the reaction was essentially the detonation. The Chapman-Jouguet $(\mathrm{CJ})$ conditions are listed in Table 1. A JWL EOS of the following form

$$
P=A\left(1-\frac{\omega}{R_{1} V}\right) e^{-R_{1} V}+B\left(1-\frac{\omega}{R_{2} V}\right) e^{-R_{2} V}+\frac{\omega E}{V},
$$

was used for the explosive material and detonation products. The parameters used are listed in Table 2. The JWL parameters were defined for the Al/air mixture based on the behaviour of such mixtures under shock loading. The rate of the reaction was derived from the detonation velocity.

Table 1. Detonation conditions assumed in the computational thermochemical code for the $\mathrm{Al} / \mathrm{air}$ explosion.

\begin{tabular}{cccccc}
\hline $\mathbf{P}(\mathrm{GPa})$ & $\mathbf{U C J}(\mathbf{k m} / \mathbf{s})$ & $\mathbf{V}(\mathbf{c c} / \mathbf{g})$ & $\mathbf{T}(\mathbf{K})$ & $\mathbf{C ~ ( k m / s )}$ & $\gamma$ \\
\hline 0.002 & 1.166 & 192.557 & 3108.4 & 0.602 & 0.954 \\
\hline
\end{tabular}

Table 2. JWL parameters assumed in the computational thermochemical code for the detonation products.

\begin{tabular}{cccccccc}
\hline Material & $\boldsymbol{\rho}_{\mathbf{o}}(\mathrm{g} / \mathbf{c c})$ & $\mathbf{A}(\mathbf{G P a})$ & $\mathbf{B}(\mathbf{G P a})$ & $\mathbf{R}_{\mathbf{1}}$ & $\mathbf{R}_{\mathbf{2}}$ & $\boldsymbol{\omega}$ & $\mathbf{E}_{\mathbf{o}}(\mathbf{k J} / \mathbf{c c})$ \\
\hline explosive & 2.68 & $1.43 \times 10^{-1}$ & $-5.6 \times 10^{-4}$ & 21.875 & 0.33 & 0.3507 & 0 \\
\hline detonation products & 2.68 & $2.86 \times 10^{-2}$ & $2.8 \times 10^{-3}$ & 7.0 & 0.50 & 0.3507 & $2.4 \times 10^{-3} *$ \\
\hline
\end{tabular}

* This value was adjusted to $2.7 \times 10^{-3}$ after initial simulations of the $100 \mathrm{~g}$ case to better match the test data.

\section{Identification and Validation}

\subsection{Identification-Simulation of $100 \mathrm{~g}$ Tests}

The parameters defined in Section 2 were used to simulate the $100 \mathrm{~g}$ tests and identify a set of explosive parameters. The initial condition was that there was a $37.04 \mathrm{cc} \mathrm{Al} /$ air cloud. Figure 6 shows the sequence of images from the simulation. The contour maps for the concentration of reacting mixture (Al/air), the reaction products, the density, and the pressure are shown at four selected time points. The time noted is relative to $t=0$ for the tests. Figure 7 shows a comparison between the test data for the pressure-time histories recorded during the simulation at the 1 and $2 \mathrm{~m}$ locations. 
(a) Al/air mixture

(b) detonation product

(c) density $\left(\mathrm{kg} / \mathrm{m}^{3}\right)$

(d) pressure $(\mathrm{Pa})$
$18.1 \mathrm{~ms}$
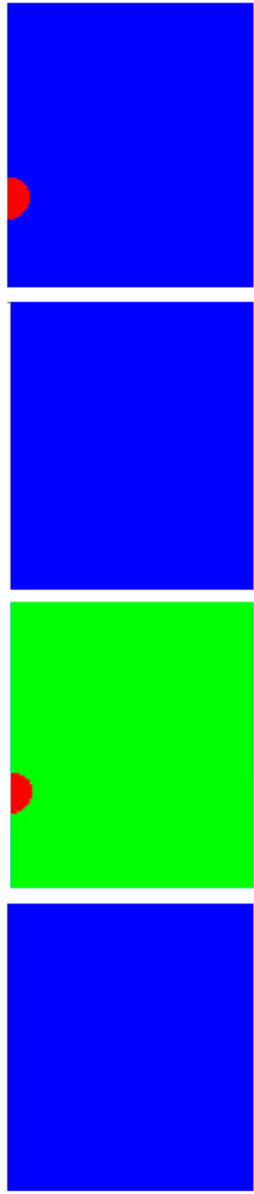

$18.9 \mathrm{~ms}$
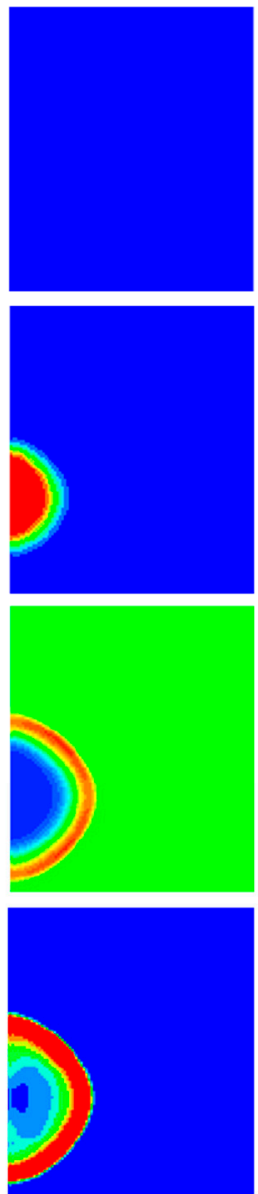

$20.1 \mathrm{~ms}$
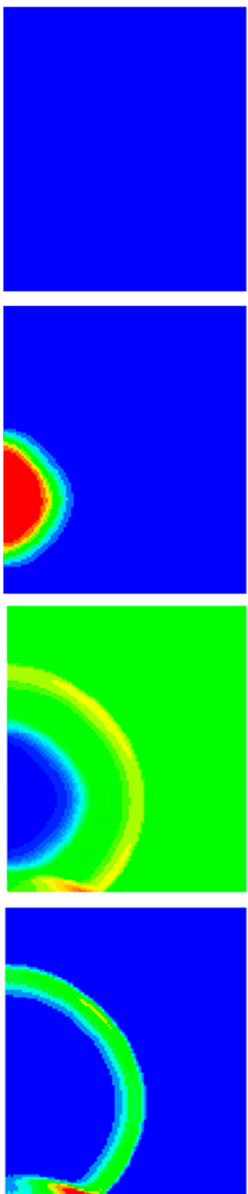

$22.5 \mathrm{~ms}$
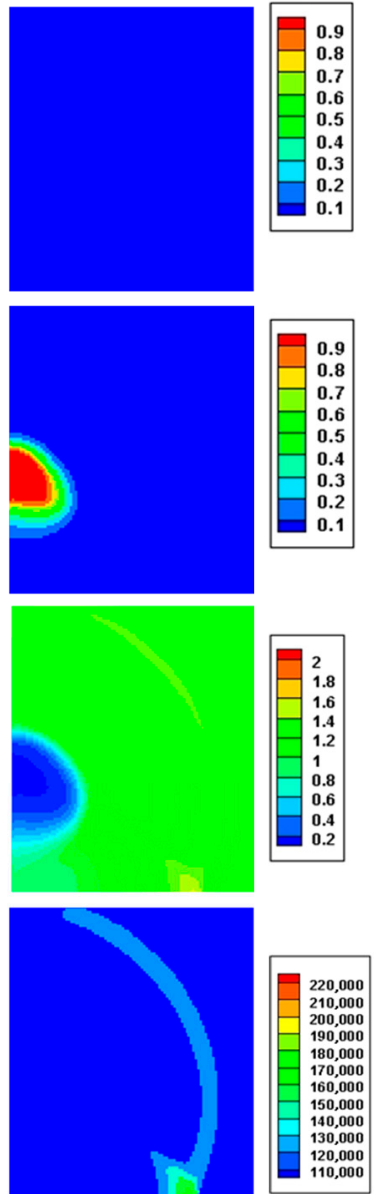

Figure 6. Sequence of images from the $100 \mathrm{~g}$ test simulation: (a) Al/air mixture concentration; (b) detonation product concentration; (c) density; and (d) pressure are shown at four time points.

The initial pulses in pressure at both locations were similar to the test data in both magnitude and duration. The secondary pulses due to ground reflection were somewhat lower in magnitude and were delayed compared to the test data. This difference could be due to slight differences in the heights. There was an intermediate pulse in one of the $1 \mathrm{~m}$ test recordings. While the cause of this pulse was not clear, it was not seen in the simulation results.

These results suggest that the predominant release of energy from the combustion of the $\mathrm{Al}$ /air cloud can be represented as a sudden event, or, as we label it here, the "explosion". It appears that the combustion event was essentially a mixing-controlled process. The explosion did not occur until the mass of $\mathrm{Al}$ powder expanded to the point where there was sufficient oxidation. Based on the size of the cloud at the time of the explosion and the mass of the Al powder, the cloud distribution was approximately $70 \%$ $\mathrm{Al}$ and 30\% air by mass, providing an oxidiser-to-fuel mole ratio (moles $\mathrm{O} / \mathrm{moles} \mathrm{Al}$ ) of 0.17, far below the stoichiometric ratio for the reaction in Equation (1). 
$100 \mathrm{~g}$ Tests

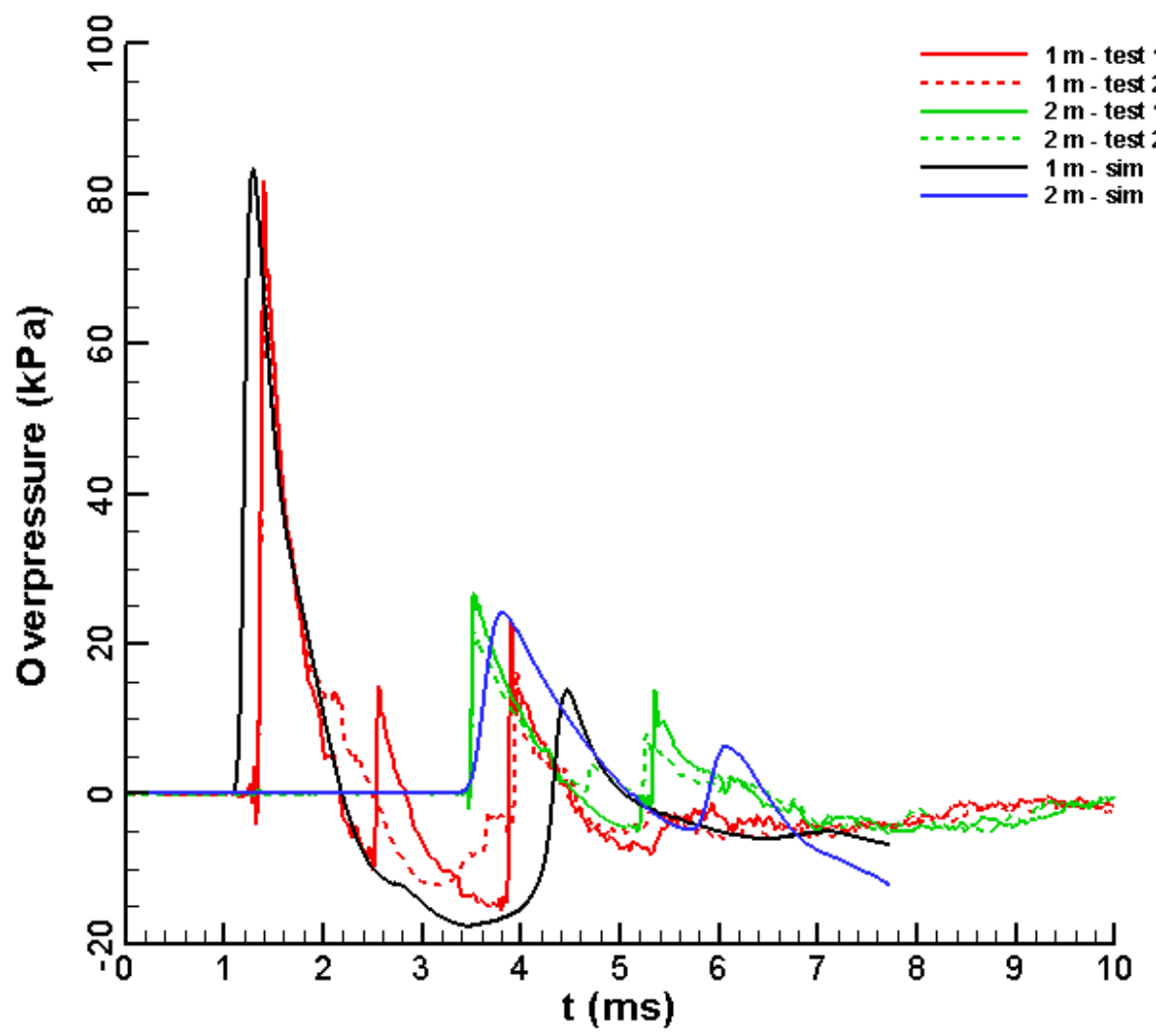

Figure 7. Comparisons between the test data and simulated values for the pressure versus time history at the 1 - and $2 \mathrm{~m}$ locations for the $100 \mathrm{~g}$ charge.

\subsection{Validation-Simulation of the $500 \mathrm{~g}$ Tests}

The $500 \mathrm{~g}$ tests were simulated in the validation stage. The same modelling parameters were used in terms of EOS and the rate of reaction. First, the test imagery was used to estimate the size of the spherical Al/air cloud at the point at which there was a noticeable sudden release of energy (i.e., the "explosion"). Three videos were reviewed, and the time of the explosion varied from approximately 3 to $6 \mathrm{~ms}$. The size of the cloud was estimated to be approximately $52 \mathrm{~cm}$ in diameter. This diameter would result in a cloud composed of $84 \% \mathrm{Al}$ and $16 \%$ air by mass. Although the fuel-to-oxidiser ratio changed slightly from the $100 \mathrm{~g}$ case, the same parameters used in that case were applied. The pressure-time histories predicted at the 1 and $2 \mathrm{~m}$ locations are shown in Figure 8. At both locations, the peak simulated pressures were lower than the peak measured pressures. 


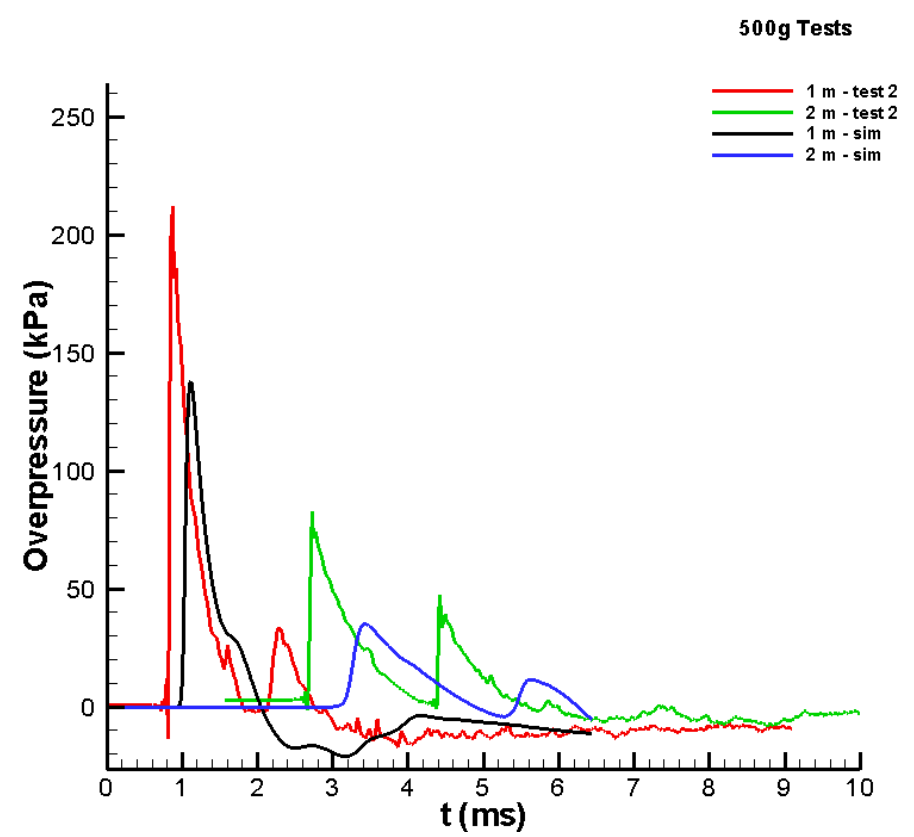

Figure 8. Comparison between test data and simulated values for the pressure versus time history for the $500 \mathrm{~g} \mathrm{Al} /$ air cloud with a $52 \mathrm{~cm}$ diameter.

Because the cloud estimated from the video produced a lower output, several cloud sizes were applied until a good match between the measured and simulated pressure-time histories was achieved. Figure 9 shows the results when the diameter of the $\mathrm{Al} /$ air cloud was assumed to be $63 \mathrm{~cm}$. The comparison is moderately good, wherein the peaks at the $2 \mathrm{~m}$ location are slightly lower than those in the test data. Using the assumed size of the cloud and the mass of $\mathrm{Al}$, the cloud was found to be $75 \% \mathrm{Al}$ and $25 \%$ air by mass. This result was similar to the ratio found for the $100 \mathrm{~g}$ results. The study presented shows that combining the experimental and advanced numerical approaches creates the ability to obtain the synergic effect for better understanding the physical phenomena, similar to [28].

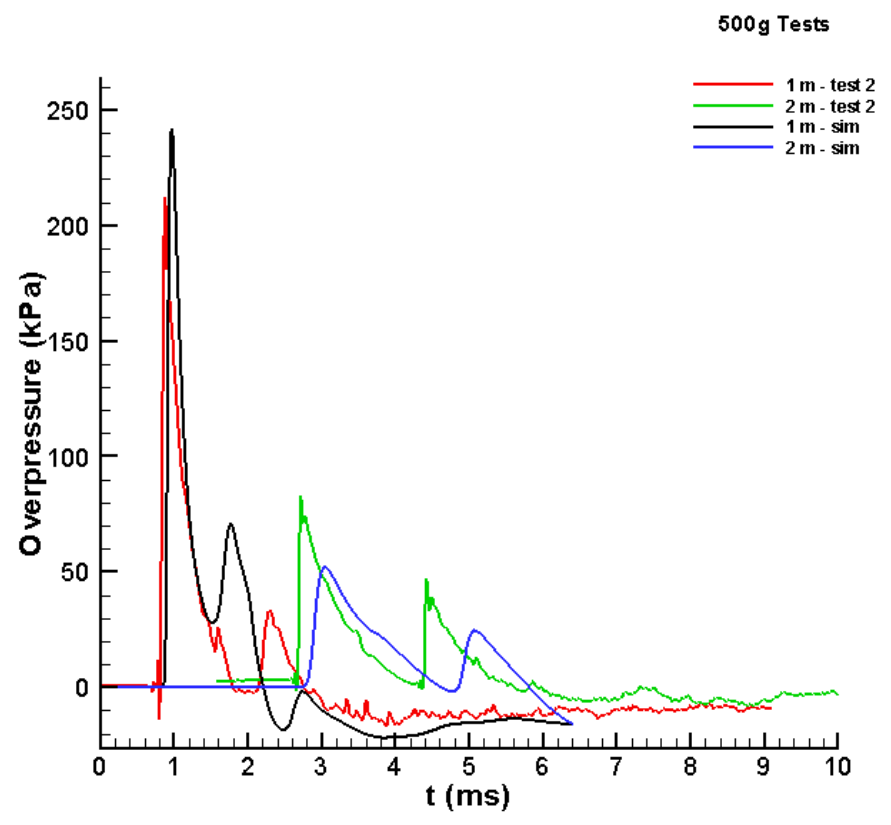

Figure 9. Comparison between test data and simulated values for the pressure versus time history for the $500 \mathrm{~g} \mathrm{Al} /$ air cloud with a $63 \mathrm{~cm}$ diameter. 


\section{Conclusions}

Combustion is the key process in many energetic systems. In this paper, the combustion of Al was investigated using a series of tests and simulations, which has not been published previously in the literature. Here, the Al was isolated and allowed to react with just oxygen in ambient air; the oxidation arose from the detonation products. The results of the $100 \mathrm{~g}$ and $500 \mathrm{~g} \mathrm{Al}$ charges indicated that the sudden explosions occurred when a mixture of $70-75 \% \mathrm{Al}$ and $30-25 \%$ air, by mass, was obtained.

Among others, the novelty of the paper is that the output from the explosions was replicated using the JWL state equation for the product and assuming detonation of the mixture. The detonation was modelled using a prescriptive method that set the burn rate based on the detonation velocity. The delay from the initiation of the event until the time of the explosion is currently under investigation. Further studies will aim to determine whether this delay is related to the time required for the gasification of the Al or the event is a mixing-controlled process.

Author Contributions: Conceptualisation, J.K.C. and P.W.S.; methodology, J.K.C. and P.W.S.; software, P.W.S.; validation, J.K.C., R.S., W.S. and P.W.S.; formal analysis, J.K.C., R.S., W.S., T.G. and P.W.S.; investigation, J.K.C. and P.W.S.; resources, M.M. and T.G.; data curation, M.M. and T.G.; writing-original draft preparation, J.K.C., P.W.S. and T.G.; writing-review and editing, P.W.S., R.S., T.G., M.M., W.S. and P.P.; visualisation, T.G., M.M. and P.P.; supervision, W.S., T.G. and P.W.S.; project administration, P.W.S. and T.G.; funding acquisition, P.W.S., W.S. and P.P. All authors have read and agreed to the published version of the manuscript.

Funding: This research was funded by the National Centre for Research and Development Poland under the grant DOB-BIO10/01/02/2019 within the framework of the Defence and Security Programme.

Data Availability Statement: The data presented in this study are available on request from the corresponding author.

Conflicts of Interest: The authors declare no conflict of interest. The funders had no role in the design of the study; in the collection, analyses, or interpretation of data; in the writing of the manuscript; or in the decision to publish the results.

\section{References}

1. Xiang, D.; Rong, J.; He, X.; Feng, Z. Underwater Explosion Performance of RDX/AP-Based Aluminized Explosives. Central Eur. J. Energetic Mater. 2017, 14, 60-76. [CrossRef]

2. Rubio, M.A.; Rubio, M.A.; Gunduz, I.E.; Gunduz, I.E.; Groven, L.J.; Groven, L.J.; Sippel, T.R.; Sippel, T.R.; Han, C.W.; Han, C.W.; et al. Microexplosions and ignition dynamics in engineered aluminum/polymer fuel particles. Combust. Flame 2017, 176, 162-171. [CrossRef]

3. Nie, H.-Q.; Chan, H.Y.; Pisharath, S.; Hng, H.H. Combustion characteristic and aging behavior of bimetal thermite powders. Def. Technol. 2020, 17, 755-762. [CrossRef]

4. Liu, P.; Liu, J.; Wang, M. Ignition and combustion of nano-sized aluminum particles: A reactive molecular dynamics study. Combust. Flame 2019, 201, 276-289. [CrossRef]

5. Gang, L.; Niu, L.; Hao, W.; Liu, Y.; Zhang, C. Atomistic insight into the microexplosion-accelerated oxidation process of molten aluminum nanoparticles. Combust. Flame 2020, 214, 238-250. [CrossRef]

6. Karasev, V.V.; Onischuk, A.A.; Glotov, O.G.; Baklanov, A.M.; Maryasov, A.G.; Zarko, V.E.; Panfilov, V.N.; Levykin, A.I.; Sabel-feld, K.K. Formation of charged aggregates of $\mathrm{Al}_{2} \mathrm{O}_{3}$ nanoparticles by combustion of aluminum droplets in air. Combust. Flame 2004, 138, 40-54. [CrossRef]

7. $\quad$ Lewis, W.K.; Rumchik, C.G.; Smith, M.J.; Fernando, K.A.S.; Crouse, C.A.; Spowart, J.E.; Guliants, E.A.; Bunker, C.E. Comparison of post-detonation combustion in explosives incorporating aluminum nanoparticles: Influence of the passivation layer. J. Appl. Phys. 2013, 113, 044907. [CrossRef]

8. Gordon, J.M.; Gross, K.C.; Perram, G.P. Fireball and shock wave dynamics in the detonation of aluminized novel munitions. Combust. Explos. Shock Waves 2013, 49, 450-462. [CrossRef]

9. Peuker, J.M.; Lynch, P.; Krier, H.; Glumac, N. Optical depth measurements of fireballs from aluminized high explosives. Opt. Lasers Eng. 2009, 47, 1009-1015. [CrossRef]

10. Carney, J.R.; Miller, J.S.; Gump, J.C.; Pangilinan, G.I. Time-resolved optical measurements of the post-detonation combustion of aluminized explosives. Rev. Sci. Instrum. 2006, 77, 063103. [CrossRef] 
11. Togashi, F.; Baum, J.D.; Soto, O.A.; Löhner, R.; Zhang, F. Numerical simulation of TNT-Al explosives in explosion chamber. In Proceedings of the Seventh International Conference on Computational Fluid Dynamics (ICCFD7), Big Island, HI, USA, 9-13 July 2012.

12. Miller, P.J. A Reactive Flow Model with Coupled Reaction Kinetics for Detonation and Combustion in Non-Ideal Explosives. MRS Proc. 1995, 418, 413. [CrossRef]

13. Liu, Y.; Wang, H.; Bai, F.; Huang, F.; Hussain, T. A New Equation of State for Detonation Products of RDX-Based Aluminized Explosives. Propellants Explos. Pyrotech. 2019, 44, 1293-1301. [CrossRef]

14. Balakrishnan, K.; Menon, S. On the Role of Ambient Reactive Particles in the Mixing and Afterburn behind Explosive Blast Waves. Combust. Sci. Technol. 2010, 182, 186-214. [CrossRef]

15. Xiao, L.-Q.; Fan, X.-Z.; Li, J.-Z.; Qin, Z.; Fu, X.-L.; Pang, W.-Q.; Wang, Y. Effect of Al content and particle size on the combustion of HMX-CMDB propellant. Combust. Flame 2020, 214, 80-89. [CrossRef]

16. Yue, J.-Z.; Duan, Z.-P.; Zhang, Z.-Y.; Ou, Z.-C. Research on Equation of State For Detonation Products of Aluminized Explosive. J. Energetic Mater. 2017, 35, 1-9. [CrossRef]

17. Baranowski, P.; Kucewicz, M.; Gieleta, R.; Stankiewicz, M.; Konarzewski, M.; Bogusz, P.; Pytlik, M.; Małachowski, J. Fracture and fragmentation of dolomite rock using the JH-2 constitutive model: Parameter determination, experiments and simulations. Int. J. Impact Eng. 2020, 140, 103543. [CrossRef]

18. Sielicki, P.W.; Łodygowski, T. Masonry wall behaviour under explosive loading. Eng. Fail. Anal. 2019, 104, 274-291. [CrossRef]

19. Baranowski, P.; Małachowski, J.; Mazurkiewicz, Ł. Local blast wave interaction with tire structure. Def. Technol. 2020, 16, 520-529. [CrossRef]

20. Yu, V.; Frolov, P.; Pokhil, P.F.; Logachev, V.S. Ignition and combustion of powdered aluminum in high-temperature gaseous media and in a composition of heterogeneous condensed systems. Combust. Explos. Shock Waves 1972, 8, 168-187.

21. Gajewski, T.; Sielicki, P.W. Experimental study of blast loading behind a building corner. Shock Waves 2020, 30, 385-394. [CrossRef]

22. Warnstedt, P.; Gebbeken, N. Innovative protection of urban areas-Experimental research on the blast mitigating potential of hedges. Landsc. Urban Plan. 2020, 202, 103876. [CrossRef]

23. Sielicki, P.W.; Pludra, A.; Przybylski, M. Experimental measurement of the bullet trajectory after perforation of a chambered window. Int. J. Appl. Glass Sci. 2019, 10, 441-448. [CrossRef]

24. Sielicki, P.W.; Ślosarczyk, A.; Szulc, D. Concrete slab fragmentation after bullet impact: An experimental study. Int. J. Prot. Struct. 2019, 10, 380-389. [CrossRef]

25. Clutter, J.K. Application of Computational Modeling for Explosive Hazard Assessments. Int. J. Prot. Struct. 2013, 4, 293-314. [CrossRef]

26. Luo, H.; Baum, J.D.; Löhner, R. On the computation of multi-material flows using ALE formulation. J. Comput. Phys. 2004, 194, 304-328. [CrossRef]

27. Liou, M.-S. Progress towards an improved CFD method-AUSM+. In Proceedings of the 12th Computational Fluid Dynamics Conference, San Diego, CA, USA, 19-22 June 1995. [CrossRef]

28. Maier, G.; Bolzon, G.; Buljak, V.; Garbowski, T.; Miller, B. Synergistic Combinations of Computational Methods and Ex-Periments for Structural Diagnosis, Computer Methods in Mechanic; Kuczma, M., Wilmanski, K., Eds.; Springer: Berlin/Heidelberg, Germany, 2010; pp. 453-476. 